\title{
A NEW RECORD OF BULBOPHYLLUM SECTION AESCHYNANTHOIDES FROM VIETNAM
}

\author{
Vuong Ba Truong ${ }^{1 *}$, JaAp J. Vermeulen ${ }^{2} \&$ Tam Quang Truong ${ }^{1}$ \\ ${ }^{1}$ Institute of Tropical Biology - Vietnam Academy of Science and Technology, 85 Tran Quoc Toan, \\ Dist.3, Ho Chi Minh City, Vietnam \\ ${ }^{2}$ Jk.art and science - Lauwerbes 8, 2318 AT Leiden, The Netherlands \\ *Author for correspondence: bavuong2019@yahoo.com
}

\begin{abstract}
Bulbophyllum hainanense is an addition to the Flora of Vietnam. Previously, Vietnamese material of this species was listed as Bulbophyllum hymenanthum, a similar-looking species. This paper provides a description and illustration of the Vietnamese material of $B$. hainanense.
\end{abstract}

KEY WORDS: Bulbophyllum hainanense, Hon Ba nature reserve, new record, Vietnam

Introduction. The genus Bulbophyllum Thouars is one of the largest plant genera, with well over 2,000 species in the tropics and subtropics worldwide (Pridgeon et al. 2014). So far, 123 species in 14 sections have been recorded for Vietnam (Averyanov \& Averyanova 2003, Averyanov et al. 2016, Truong \& Sridith 2016, Averyanov et al. 2017, Nguyen \& Averyanov 2017, Averyanov et al. 2018). We add another species to the list: B. hainanense Z.H.Tsi, found in Hon Ba nature reserve, Khanh Hoa province.

According to Pridgeon et al. (2014) it belongs to section Aeschynanthoides Carr (1930). Species of this section resemble species of section Stachysanthes (Blume) Averyanov (1994) in the sense that both have minute pseudobulbs, racemose inflorescences, and flowers of rather simple structure. The distinguishing feature of Sect. Aeschynanthoides is the node displacement at the base of the flower: the floral bract is attached well below the basal node of the pedicel (Fig. 1C, left). In section Stachysanthes the basal node of the pedicel is at the same level with the floral bract attachment. In addition, the flowers are lemon yellow, and/or purple staining predominate in Sect. Aeschynanthoides, whereas the flowers in species of section Stachysanthes are usually white or creamy yellow, less frequently ochre-orange or brick-red. Purple staining occurs only sporadically in section Stachysanthes. Because of an error in the key to the species in Chen and Vermeulen (2009), both $B$. drymoglossum Maxim. and B. hainanense were incorrectly placed in section Stachysanthes instead of Aeschynanthoides.
So far, only a single species of sect. Aeschynanthoides was known from Vietnam: B. hymenanthum Hook.f. (Seidenfaden 1992, Averyanov 1994, Averyanov \& Averyanova 2003). Bulbophyllum hainanense is the second species recorded for Vietnam. We present pictures of both for comparison.

Materials and methods. The description of Bulbophyllum hainanense is based on the living material found in Hon Ba nature reserve, Khanh Hoa province. The measurements and description were prepared from living plants. Material was preserved in $70 \%$ ethanol and stored at VNM herbarium (ITB - Ho Chi Minh City). All the photos were taken with a Canon 600D fitted with an EF-S 60mm f/2.8 Macro USM lens. The information and the pictures of B. hymenanthum (Fig. 2) from Vietnam are provided by Mr. Van Canh Nguyen from Nam Nung Nature Reserve. Terminology for the morphological description follows Beentje (2012).

\section{TAXONOMIC TREATMENT}

\section{Bulbophyllum hainanense Z.H.Tsi (Fig. 1)}

TYPE: China. Hainan: on a tree in forest, 500 m, Nov. 1978, Z.H. Tsi 1 (holotype: PE!).

Epiphytic herb. Rhizome creeping, slender. Pseudobulb minute, not or hardly thicker than the rhizome. Leaves sessile, fleshy, broadly elliptic, $c a .10$ $12 \mathrm{~mm}$ long, 6-8 $\mathrm{mm}$ wide, apex acute. Inflorescence from the base of the pseudobulbs, erect, $c a .2 .5 \mathrm{~cm}$ long; 1-2-flowered; peduncle bracts 3, with 1 approx. 


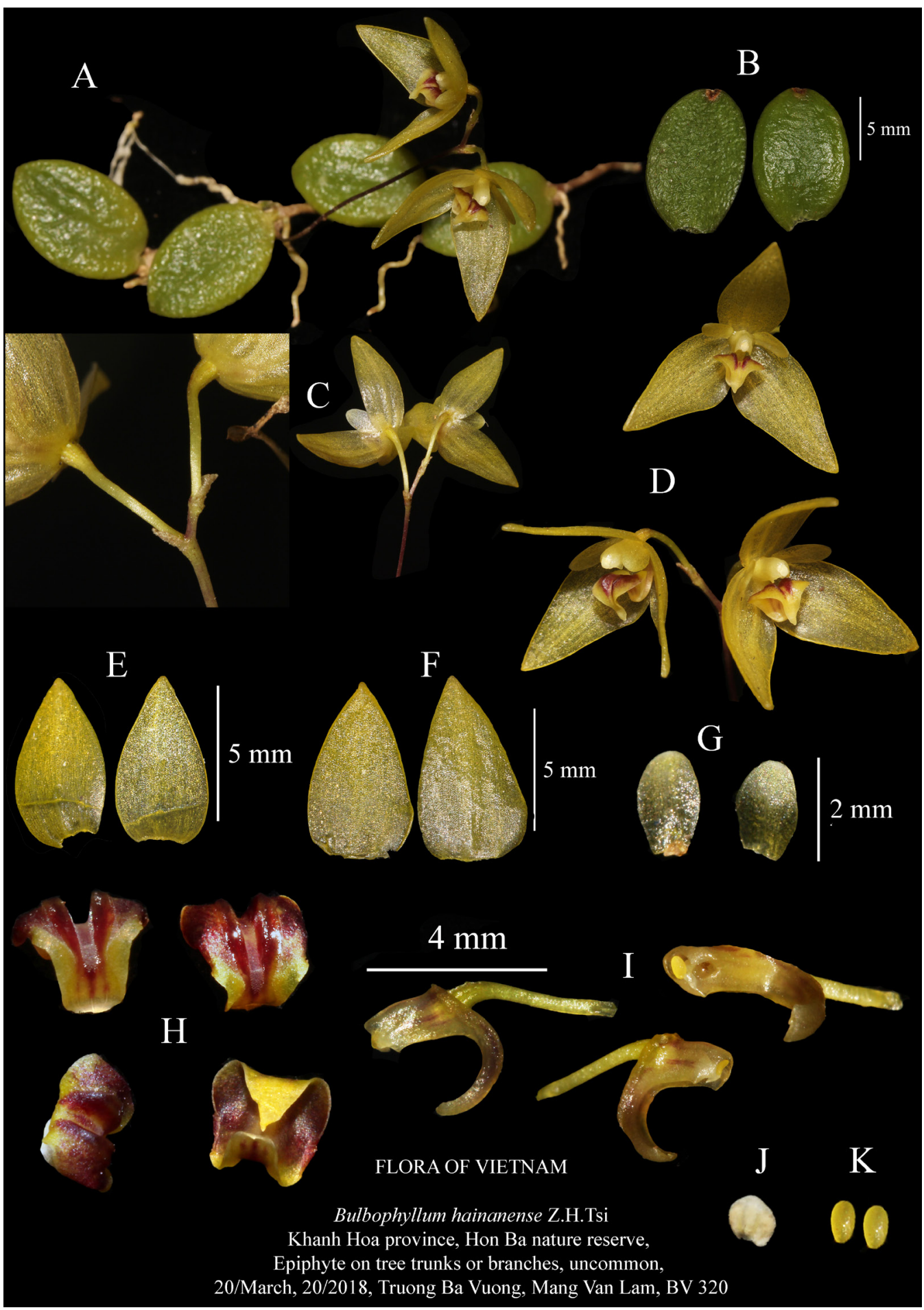

Figure 1. Bulbophyllum hainanense Z.H.Tsi. A. Flowering plant; B. Leaves; C. Pedicel and flowering bract; D. Opening flowers; E. Dorsal sepal; F. Lateral sepals; G. Petals; H. Labellum in views; I. Column and pedicel; J. Anther cap; K. Pollinia. Photos by TRUONG Ba Vuong, 2018. 

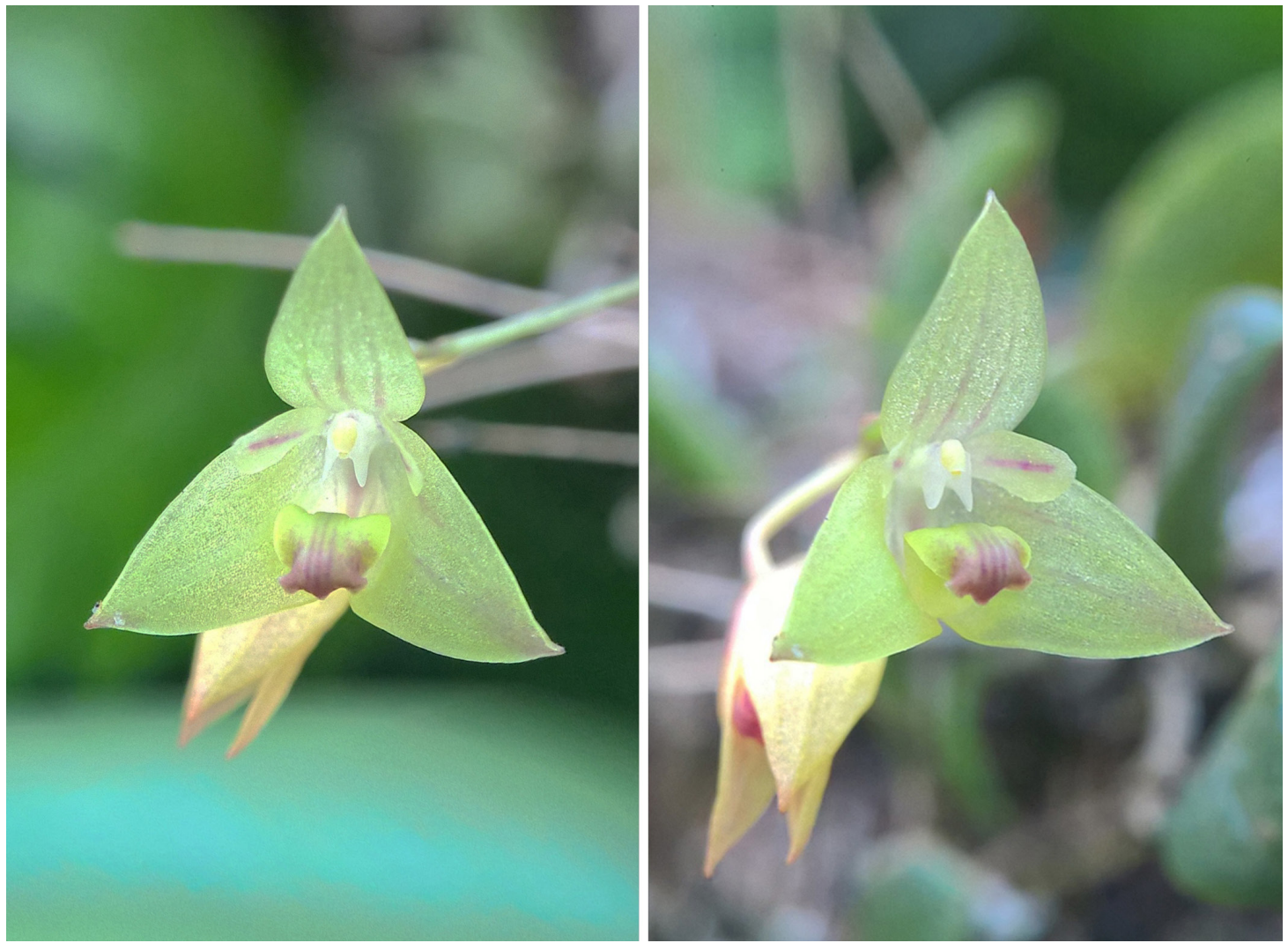

FIGURE 2. Bulbophyllum hymenanthum Hook.f., two views. Photos by NGUYEN Van Canh, 2018.

half-way the peduncle, the longest $c a .1 .8 \mathrm{~mm}$ long. Rachis ca. $2 \mathrm{~mm}$ long, floral bracts $c a .1 .5 \mathrm{~mm}$ long. Flowers wide open, sepals and petals yellow, labellum yellow with purple ridges; pedicel plus ovary $6.0-6.5$ $\mathrm{mm}$ long, basal node $c a .0 .4 \mathrm{~mm}$ above the floral bract attachment. Dorsal sepal ovate, ca. $6 \mathrm{~mm}$ long, $4 \mathrm{~mm}$ wide apex acute; lateral sepals free ovate, $c a .7 \mathrm{~mm}$ long, $4 \mathrm{~mm}$ wide, apex acute. Petals elliptic, ca. $2 \mathrm{~mm}$ long, $1 \mathrm{~mm}$ wide, apex rounded. Labellum distinctly curved, thin, ovate, tapering towards the apex, acute, glabrous; adaxially with two ridges starting near the base and continuing up to $2 / 3$ along the length of the lip, channeled in between. Column yellow, ca. $1.8 \mathrm{~mm}$ long, stelidia deltoid, acute, with a small, triangular, acute tooth along the lower margin. Anther cap with a slight, rounded ridge towards its base. Pollinia 2, elliptic.

Distribution in Vietnam: Hon Ba nature reserve only, in Khanh Hoa province (BV 320, VNM). Distribution elsewhere: China, Hainan.
ECOLOGY: Epiphytic, usually on tree trunks, sometimes on branches, above $1000 \mathrm{~m}$ a.s.l.

Cross Diagnosis: Within section Aeschynanthoides, it shares the presence of two ridges on the adaxial side of the lip with $B$. drymoglossum Maximovich (1887), but differs by the tapering, acute lip apex. It differs from B. hymenanthum (the other species of section Aeschynanthoides native to Vietnam, Fig. 2) by the minute, triangular tooth along the lower edge of the stelidia; in B. hymenanthum a conspicuous, rounded wing is present.

ACKNOWLEDGMENTS. The authors would like to express their sincere gratitude to the reviewers for their critical suggestions that were helpful in improving the manuscript. The authors would like to thank Mr. Nguyen Van Canh for his making his pictures of B. hymenanthum available to us. They also thank Mr. Do Anh Thy, Mr. Mang Van Lam, and the staff of Hon Ba nature reserve for their kind support. A sincere thank you to Jim Cootes, Joe Chun-Chia Huang, CE Neuvo for their diligent proofreading. 


\section{Literature Cited}

Averyanov, L. V. (1994). Identification guide to Vietnamese orchids (Orchidaceae Juss.). Saint Petersburg: World and Family.

Averyanov, L. V. \& Averyanova, A. L. (2003). Updated checklist of the orchids of Vietnam. Hanoi: Vietnam National University Publishing House.

Averyanov, L. V., Nguyen, S. K., Nong, V. D., Nguyen, V. C., Truong, B. V. \& Maisak, T. V. (2017). Bulbophyllum sect. Hirtula in eastern Indochina. Taiwania, 62(1), 1-23.

Averyanov, L. V., Nong, V. D., Nguyen, S. K., Maisak, T. V., Nguyen, V. C., Phan, Q. T., Nguyen, P. T., Nguyen, T. T. \& Truong, B. V. (2016). New species of orchids (Orchidaceae) in the Flora of Vietnam. Taiwania, 61 (4), 319-354.

Averyanov, L. V., Nong, V. D., Nguyen, H. T., Nuraliev, M. S., Maisak, T. V. \& Nguyen, C. A. (2018). New species of Bulbophyllum (Orchidaceae) in the flora of Vietnam. Phytotaxa, 369 (1), 1-14.

Beentje, H. (2012). The Kew Plant Glossary, an illustrated dictionary of plant terms (revised edition). Kew: Royal Botanic Gardens, Kew Publishing.

Carr, C. E. (1930). Some Malayan orchids, 2. Gardens'Bulletin Straits Settlements, 5, 124-160.

Chen, S. C. \& Vermeulen, J. J. (2009). Bulbophyllum. Pp. 404-440 in: Z. G. Wu, P. H. Raven, D.Y. Hong (eds.), Flora of China 25. Beijing \& St. Louis: Science Press \& MBG Press.

Liu, Q., Li, J. W., Jin, X. H., \& Gao, J. Y. (2015). A new species of Bulbophyllum (Orchidaceae; Epidendroideae; Dendrobiinae) from Yunnan, China. Phytotaxa, 236 (3), 287-290.

Hooker, J. D. (1886-1890). Flora of British India Vol. 5. London: L. Reeve \& Co. Pp. 1-910.

Maximovich, C. J. (1887). Bulbophyllum drymoglossum Maxim. Botanical Magazine (= Shokubutsugaku zasshi) (Tokyo) $1,1,14$.

Nguyen, H. T. \& Averyanov, L. V. (2017). Two endangered ornamental orchid species, Bulbophyllum coweniorum and Esmeralda bella (Orchidaceae), new in the flora of Vietnam. Turczaninowia, 20(1), 68-74.

Pridgeon, A. M., Cribb, P. J., Chase, M. W. \& Rasmussen, F. N. (2014). Bulbophyllum. Pp. 4-51 In: Genera Orchidacearum vol. 6, Epidendroideae (part three). Oxford: Oxford University Press.

Seidenfaden, G. (1992). The orchids of Indochina. Opera Bot., 114, 1-502.

Truong, B. V. \& Sridith, K. (2016). The phytogeographic note on the orchid's flora of Vietnam: a case study from the Hon Ba Nature Reserve, Central Vietnam. Taiwania, 61(2), 127-140. 